\title{
Calcium Binding and Transport by Coenzyme Q
}

\author{
Ivan Bogeski, ${ }^{+, \|}$Rubin Gulaboski, ${ }^{*,+,, \S, \|}$ Reinhard Kappl, ${ }^{\dagger}$ Valentin Mirceski, $^{\S}$ Marina Stefova, ${ }^{\S}$ \\ Jasmina Petreska, ${ }^{\mathcal{S}}$ and Markus Hoth ${ }^{*,+}$ \\ ${ }^{\dagger}$ Department of Biophysics, School of Medicine, Saarland University, 66421 Homburg, Germany \\ ${ }^{\ddagger}$ Department of Chemistry, Faculty of Agriculture, University Goce Delcev, Stip, Macedonia \\ ${ }^{\S}$ Institute of Chemistry, Faculty of Natural Sciences and Mathematics, "SS Cyril and Methodius” University, PO Box 162, 1000, Skopje, \\ Macedonia \\ Supporting Information
}

\begin{abstract}
Coenzyme Q10 (CoQ10) is one of the essential components of the mitochondrial electron-transport chain (ETC) with the primary function to transfer electrons along and protons across the inner mitochondrial membrane (IMM). The concomitant proton gradient across the IMM is essential for the process of oxidative phosphorylation and consequently ATP production. Cytochrome P450 (CYP450) monoxygenase enzymes are known to induce structural changes in a variety of compounds and are expressed in the IMM. However, it is

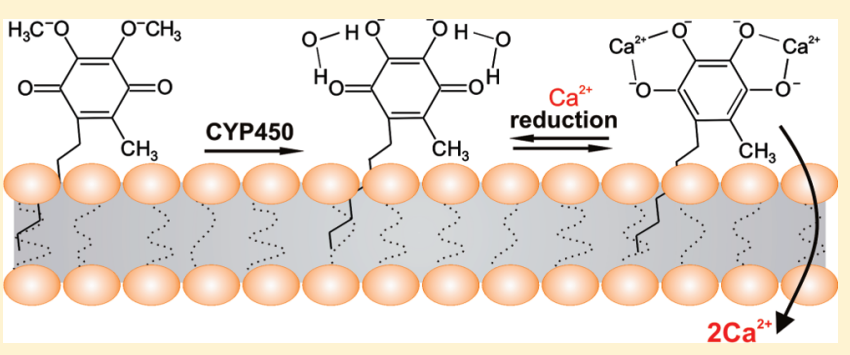
unknown if CYP450 interacts with CoQ10 and how such an interaction would affect mitochondrial function. Using voltammetry, UV-vis spectrometry, electron paramagnetic resonance (EPR), nuclear magnetic resonance (NMR), fluorescence microscopy and high performance liquid chromatography-mass spectrometry (HPLC-MS), we show that both CoQ10 and its analogue CoQ1, when exposed to CYP450 or alkaline media, undergo structural changes through a complex reaction pathway and form quinone structures with distinct properties. Hereby, one or both methoxy groups at positions 2 and 3 on the quinone ring are replaced by hydroxyl groups in a time-dependent manner. In comparison with the native forms, the electrochemically reduced forms of the new hydroxylated CoQs have higher antioxidative potential and are also now able to bind and transport $\mathrm{Ca}^{2+}$ across artificial biomimetic membranes. Our results open new perspectives on the physiological importance of CoQ10 and its analogues, not only as electron and proton transporters, but also as potential regulators of mitochondrial $\mathrm{Ca}^{2+}$ and redox homeostasis.
\end{abstract}

\section{INTRODUCTION}

Coenzyme Q10 (CoQ10, Ubiquinone 50, or 2,3-dimethoxy5-methyl-6-decaprenyl-1,4-benzoquinone) is a lipid-soluble compound, indispensable for optimal functioning of all living organisms. ${ }^{1-4}$ As the only nonprotein component of the mitochondrial electron-transport chain (ETC), CoQ10 is a central electron carrier between the mitochondrial reductases (complex I and II) and complex III, simultaneously transferring protons from the mitochondrial matrix to the intermembrane space. The concomitant proton gradient across the inner mitochondrial membrane (IMM) is essential for ATP production. ${ }^{5-7}$

Apart from their main function, CoQ10 and several other coenzyme $\mathrm{Q}(\mathrm{CoQ})$ family members have additional functions in the regulation of the cellular metabolism. CoQs can act as scavengers of free radicals, regenerators of $\alpha$-tocopherol and ascorbic acid, and regulators of the mitochondrial permeability transition pore (PTP) and the mitochondrial uncoupling proteins (UCP)., ${ }^{5,6}$ Under certain conditions, in contrast to their antioxidant function, a variety of quinones in their reduced (quinol) form can also contribute to the generation of reactive oxygen species (ROS). ${ }^{8-10}$
Numerous electrochemical studies of CoQ10 have been performed to characterize its redox properties. ${ }^{11}$ However, experiments with CoQ10 dissolved in aqueous solutions are extremely difficult due to its high lipophilicity. To avoid this problem, electrochemical techniques with a preadsorption of CoQ10 on bare mercury, ${ }^{12}$ carbon, ${ }^{13-15}$ lipid modified mercury, ${ }^{16,17}$ or gold ${ }^{18}$ electrodes have been applied. In summary, the results of these studies indicate mainly a 2-electron transformation of the oxidized quinone into a reduced quinol form. The electrochemistry of CoQ10 is particularly complex, proceeding through formation of a semiquinone radical, the stability of which strongly depends on the molecular environment and $\mathrm{pH}$ of the medium. ${ }^{16}$

Bennett et al. have shown that the synthetic compound 2-palmitoylhydroquinone (2PHQ), whose redox chemistry is also based on the quinone/quinol redox couple, can bind and transfer $\mathrm{Ca}^{2+}$ ions across artificial membranes. The mechanism of $\mathrm{Ca}^{2+}$ transfer by this compound is achieved through a redox

Received: November 12, 2010

Published: May 06, 2011 
switching mechanism, principally similar to the redox-dependent proton transfer. ${ }^{19}$ In addition to this study, we recently also showed that $2 \mathrm{PHQ}$ can transfer not only $\mathrm{Ca}^{2+}$ but also $\mathrm{Ba}^{2+}$, $\mathrm{Sr}^{2+}$, and to a lower extent $\mathrm{Mg}^{2+}$ across mimetic biomembranes. ${ }^{20}$ The analysis of the mechanism and the stoichiometry of complex formation revealed that ion binding and transfer depend critically on the adjacent position of the two oxygen atoms in the $2 \mathrm{PHQ}$ molecular structure. ${ }^{19,20}$ Such an arrangement of neighboring oxygens is, however, not found in any naturally occurring CoQ compounds. Consequently, CoQs are known not to bind $\mathrm{Ca}^{2+}$ and correspondingly do not transport $\mathrm{Ca}^{2+}$ across membranes.

Considering, however, the high concentration of CoQs in mitochondrial membranes and the importance of mitochondria for cellular $\mathrm{Ca}^{2+}$ homeostasis, it is attractive to test if CoQs under certain circumstances bind and maybe even transport $\mathrm{Ca}^{2+}$. There is a big discrepancy between the importance of mitochondrial $\mathrm{Ca}^{2+}$ homeostasis and the molecular knowledge about the transport mechanisms. $\mathrm{Ca}^{2+}$ import into mitochondria and export from mitochondria are highly relevant for numerous cellular functions. ${ }^{21-24}$ Several modes of $\mathrm{Ca}^{2+}$ import into mitochondria, including a lower affinity/higher capacity and a higher affinity/lower capacity mode, have been described. ${ }^{24-26}$ However, in particular, the proteins/molecules for the ratelimiting $\mathrm{Ca}^{2+}$ import across the IMM are not known or controversially discussed. ${ }^{25,26}$ We designed experiments to test if CoQs can be chemically modified to bind and transport $\mathrm{Ca}^{2+}$ across membranes and analyzed if these modifications are also induced in a physiological context.

\section{MATERIALS AND METHODS}

Chemicals. All chemicals were purchased from Sigma-Aldrich unless indicated otherwise.

Conventional Voltammetric Experiments. Cyclic and squarewave voltammetric measurements were conducted with an AUTOLAB potentiostat model PGSTAT 12 (Eco-Chemie, The Netherlands) using a conventional three-electrode setup. $\mathrm{An} \mathrm{Ag} / \mathrm{AgCl}(3 \mathrm{M} \mathrm{KCl})$ was used as a reference electrode, while a platinum wire served as a counter electrode. The working electrode was an ultra trace graphite electrode (Metrohm, Germany) with a diameter of $1.5 \mathrm{~mm}$. The working electrode was cleaned before each experiment by polishing it with aluminum powder for $30 \mathrm{~s}$, and then rinsing it with ethanol and deionized water. If not otherwise stated, all voltammetric measurements were performed at room temperature. For each point presented at the diagrams, 10 consecutive voltammograms were made, and the average value was taken. The standard deviation of the measured potentials was $1 \mathrm{mV}$, which was the same as the value of the potential step used in the voltammetric measurements.

For the experiments in high alkaline media, CoQ1 (95\% purity) or CoQ10 (99\%) were dissolved in 0.1 or $1 \mathrm{M} \mathrm{NaOH}$ (indicated in the text or in the figure legends). The chemical reaction was quenched by titration to neutral $\mathrm{pH}(\sim 7)$ using $0.5 \mathrm{M}$ nitric acid at different time points. All aqueous solutions were prepared with deionized water and deaerated with argon. For the experiments with CYP450, $2 \mu \mathrm{M}$ CoQ10 was added to a Ringer's buffer, ( $\mathrm{pH}$ 7.4) containing $1 \mathrm{nM}$ human CYP1B1 and human NADPH-P450 reductase. Experiments were conducted at $37^{\circ} \mathrm{C}$.

Thin-Organic-Film Electrodes. To study the redox chemistry of CoQ10 and its ion-processing properties in biomimetic membranes, we used a thin-organic-film electrode setup. CoQ10 and an appropriate organic electrolyte were dissolved in a water-immiscible lipophilic organic solvent (1,2-dichlorethan, DCE), which was enriched with a suitable lipid (1,2-dioleyl-sn-glycero-3-phosphocholine). A droplet ( $1 \mu \mathrm{L})$ of the solution was then placed on the surface of the working graphite electrode, where it spreads and forms a stable film with a thickness of about $1 \mu \mathrm{m}$. The working electrode is subsequently submerged in the aqueous working solution, in which the reference and counter electrodes were placed. A liquid-liquid interface that is formed between the water solution and the lipid-modified organic phase mimics biological membranes. ${ }^{27}$ By controlling the potential difference at the electrode-membrane interface, reduction of CoQ10 in the organic film was induced, causing formation of excess of negatively charged species and a misbalance of the electroneutrality of the membrane. As compensating charge, counterions (for example $\mathrm{Ca}^{2+}$ ) are transferred across the water-organic phase. More detailed descriptions of the features of the "thin-organic-film" and the "three-phase electrode" scenarios are given elsewhere. $^{27-30}$

Fura-2-Based Measurements of $\mathrm{Ca}^{2+}$ Transport across ThinOrganic-Film Biomembranes. The transport of the $\mathrm{Ca}^{2+}$ ions from the water into the organic phase in the presence of hydroxyl CoQ acting as a facilitator in the organic phase was probed by a combination of electrochemical and partition experiments. One $\mathrm{mM} \mathrm{CoQ} 10$ was dissolved in the organic solvent nitrophenyl octyl ether (NPOE) in the presence of $2 \mathrm{mM}$ of tetraoctylammonium hydroxide $\left(\mathrm{Oct}_{4} \mathrm{~N}(\mathrm{OH})\right)$ as a donor of $\mathrm{OH}$ groups. A droplet of $5 \mu \mathrm{L}$ of this organic solution was placed on a small hole made on the surface of a highly lipophilic black graphite electrode. The modified electrode was then submerged in an aqueous solution containing $100 \mathrm{mM} \mathrm{Ca}^{2+}$, and the potential was set at $-0.6 \mathrm{~V}$ for a period of $60 \mathrm{~min}$. At this potential, hydroxyl CoQ10 in the organic droplet is continuously reduced, thus creating excess of negative charges in the organic phase. To restore the charge electroneutrality in the organic phase, $\mathrm{Ca}^{2+}$ ions are being transferred due to the electric driving force across the liquid-liquid interface from the water to the organic phase. After a period of $60 \mathrm{~min}$, the graphite electrode (with the attached organic droplet) was removed from the electrochemical cell, and the droplet was stripped into $500 \mu \mathrm{L}$ of nominally $\mathrm{Ca}^{2+}$ free water. The oxygen present in the water will cause reoxidation of the reduced hydroxylated CoQ10 in the organic phase, releasing $\mathrm{Ca}^{2+}$ ions from the organic into the water phase. This procedure was repeated 20 times for three independent experiments. As a control, NPOE without CoQ10 was used.

To determine the concentration of transferred-Ca ${ }^{2+}$, the fluorescent $\mathrm{Ca}^{2+}$ indicator Fura 2 pentapotassium salt $(5 \mu \mathrm{M}$, Invitrogen) was added to the water solution in which the electrode was stripped. A drop of the mixture was placed on a coverslip and fluorescence (excitation, 340 and $380 \mathrm{~nm}$; emission, $510 \mathrm{~nm}$ ) was measured using an Olympus IX 70 microscope equipped with a $20 \times($ UApo/340, N.A. 0.75$)$ objective, with a Polychrome V Monochromator (TILL Photonics) and a chargecoupled device camera TILL Imago (TILL Photonics). ${ }^{31}$ The $\mathrm{Ca}^{2+}$ concentration was calibrated according to Grynkiewicz at al. ${ }^{32}$

UV-Vis Measurements. For the spectrophotometric experiments, we used a UV/vis spectrophotometer Model Ultrospec 2110 pro. The UV-vis measurements were performed in the wavelength range between 200 and $900 \mathrm{~nm}$. The scan rate in the kinetic mode was 5 min.

EPR and NMR Measurements. The EPR experiments were performed at room temperature with a Bruker spectrometer (ESP300e) equipped with a TMH cavity. The modulation amplitudes varied between 0.001 and $0.02 \mathrm{mT}$ depending on the sample. The microwave power was set to 0.2 or $0.63 \mathrm{~mW}$. Spectra were recorded with scan times of 10,50 , or $90 \mathrm{~s}$ and stored consecutively to monitor the kinetic behavior of the solution. The samples were prepared either at $\mathrm{pH} 13$ or 14 in the presence or absence of oxygen (using deaerated solutions, which were filled into a flat cell (Wilmad) under nitrogen atmosphere). For reduction with sodium borhydride, $\mathrm{NaBH}_{4}$, its concentration was always one-half of the CoQ1 concentration. 
For the NMR experiments, a $400 \mathrm{MHz}$ Bruker Avance instrument was used to record standard one-dimensional proton spectra. The solutions were prepared in $\mathrm{D}_{2} \mathrm{O}$ and titrated to $\mathrm{pD}=7.0$ with $\mathrm{DNO}_{3}$ after defined reaction times in 1 or $0.1 \mathrm{M} \mathrm{NaOD}$. The samples $(600 \mu \mathrm{L})$ were filled in precision quartz tubes for measurement at $290 \mathrm{~K}$.

LC/DAD/ESI- MS ${ }^{\text {n }}$ Measurements. Chromatographic separations were carried out on a $150 \mathrm{~mm} \times 4.6 \mathrm{~mm}, 5 \mu \mathrm{m}$ XDB-C18 Eclipse column (Agilent, U.S.). The mobile phase consisted of two solvents: water-formic acid (1\%) and acetonitrile. A linear gradient was used starting with $30 \%$ acetonitrile to reach $100 \%$ acetonitrile at $30 \mathrm{~min}$. The flow rate was $0.8 \mathrm{~mL} \mathrm{~min}^{-1}$, and the injection volume was $5 \mu \mathrm{L}$. The HPLC system was equipped with an Agilent 1100 series diode array detector coupled to a mass spectrometer (Agilent Technologies, Waldbronn, Germany). It consisted of a G1312A binary pump, a G1313A autosampler, a G1322A degasser, and a G1315B photodiode array detector, controlled by ChemStation software (Agilent, v.08.03). Spectral data from all peaks were accumulated at 190-600 nm, and chromatograms were recorded at $280 \mathrm{~nm}$. The mass detector was a G2445A ion-trap mass spectrometer equipped with an electrospray ionization (ESI) system and controlled by LCMSD software (Agilent, v.6.1.). Nitrogen was used as nebulizing gas at pressure of $65 \mathrm{psi}$, and the flow was adjusted to $12 \mathrm{~L} \mathrm{~min}^{-1}$. The heated capillary temperature was $325^{\circ} \mathrm{C}$, and the voltage was $4 \mathrm{kV}$. MS data were acquired in the positive ionization mode. The full scan mass covered the $\mathrm{m} / z$ range from 15 to 500. Collision-induced fragmentation experiments were performed in the ion trap using helium as a collision gas, with voltage ramping cycle from 0.3 to $2 \mathrm{~V}$. The maximum accumulation time of the ion trap and the number of MS repetitions to obtain the MS average spectra were set at $300 \mathrm{~ms}$ and 3 , respectively.

\section{RESULTS}

High pH Induces Structural and Functional Changes of CoQ1: Voltammetric and Spectrophotometric Analysis. In contrast to CoQ10, the analogue compound CoQ1 (also known as Ubiquinone-5) is much more hydrophilic, because it contains only one instead of 10 isoprenoid groups in its side-chain. Because the length of the side-chain does not affect the redox properties of CoQs, ${ }^{15} \mathrm{CoQ} 1$ is a valuable tool to explore the redox properties of the more lipophilic CoQ members in aqueous environments by electrochemical methods. In aqueous solutions with $\mathrm{pH}$ values lower than 9 , CoQ1 is soluble in concentrations up to $\sim 100 \mu \mathrm{M}^{33}$ at room temperature, displaying a yellowish color (Figure S1A, left). Its general voltammetric behavior is briefly summarized here and is similar to that of other quinones. ${ }^{11,16,34-37}$

Electrochemically reversible behavior of CoQ1 can be obtained only in a strong acidic medium. A typical cyclic voltammetry response of CoQ1 recorded in $1 \mathrm{M} \mathrm{HCl}$ is presented in Figure S1B. It shows a well-developed peak-pair with a midpeak potential of $\sim+0.26 \mathrm{~V}$ and a peak potential separation of $\sim 39 \mathrm{mV}$ at a scan rate of $3 \mathrm{mV} / \mathrm{s}$. The latter is close to the theoretically predicted value of $30 \mathrm{mV}$, typical for a two-electron reversible electrode process. Increasing the scan rate of the potential sweep reveals that the electron exchange is an intrinsically slow process, which is manifested by enlargement of the peak-to-peak potential separation (Figure S1B). At the same time, the peak current of both peaks increases in proportion to the square root of the sweep rate, implying diffusional mass transfer of the redox species without significant contribution of adsorption phenomena. By increasing the $\mathrm{pH}$, electrochemical reversibility diminishes, thus indicating an electrode process that is significantly controlled by the electron exchange rate. A typical
Scheme 1. Redox Transformation of $\mathrm{CoQ} 1^{a}$

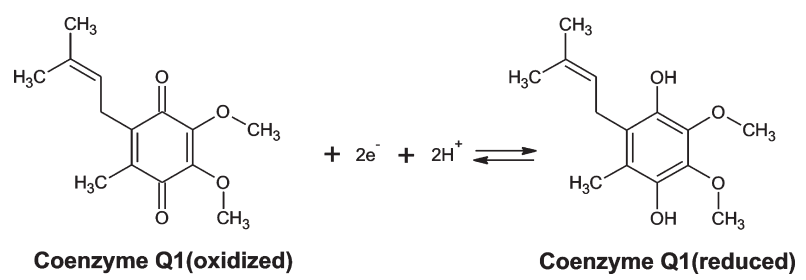

${ }^{a}$ The quinone (oxidized form of CoQ1) is reduced to the quinol (reduced form of Coenzyme Q1) via simultaneous exchange of two electrons and two protons. This reaction scheme holds for acidic, neutral, and slightly alkaline conditions.
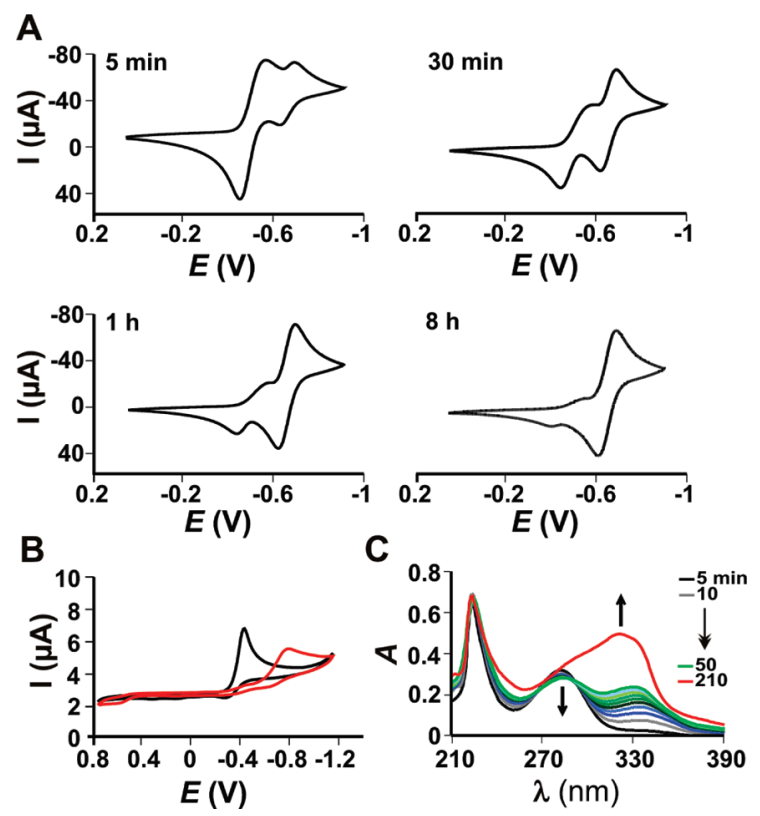

Figure 1. High $\mathrm{pH}$ induces time-dependent transformation of CoQ1. (A) CVs of $0.5 \mathrm{mM}$ CoQ1 recorded in $0.1 \mathrm{M} \mathrm{NaOH}$. The scans were recorded $5 \mathrm{~min}, 30 \mathrm{~min}, 1 \mathrm{~h}$, and $8 \mathrm{~h}$ after the addition of $0.1 \mathrm{M} \mathrm{NaOH}$. (B) (Black trace) CV of the native CoQ1 (yellow form) dissolved directly in a neutral aqueous solution; (red trace) CV of the new (purple) hydroxylated derivative of CoQ1. CoQ1 was initially in contact with $0.1 \mathrm{M} \mathrm{NaOH}$ for $6 \mathrm{~h}$. In both cases, the final $\mathrm{pH}$ was adjusted to 7.4. $c(\mathrm{CoQ} 1)=50 \mu \mathrm{M}$, scan rate was $30 \mathrm{mV} / \mathrm{s}$. (C) Time course of UV-vis kinetic spectra of $10 \mu \mathrm{M}$ CoQ1 in $0.1 \mathrm{M} \mathrm{NaOH}$.

cyclic voltammogram (CV) recorded in neutral $\mathrm{pH}$ is shown in Figure S1C. Moreover, within the $\mathrm{pH}$ interval between 1 and 11, the midpeak potential shifts in proportion to $\mathrm{pH}$ with a slope of $\sim-60 \mathrm{mV}$, implying that the overall redox process is a twoelectron two-proton transformation $\left(2 \mathrm{e}^{-} / 2 \mathrm{H}^{+}\right)$, which can be described by the turnover of the quinone/quinol (CoQ1/ $\mathrm{CoQ}_{1} \mathrm{H}_{2}$, see Scheme 1) redox couple. ${ }^{11,16,34-37}$

Contrary to the $\mathrm{pH}$ sensitivity, the CoQ1 electrochemistry is insensitive to $10 \mathrm{mM} \mathrm{Ca}^{2+}$ (Figure S1D) because the voltammograms are identical in the absence (black) or presence (red) of $\mathrm{Ca}^{2+}$. Similarly, other divalent earth alkali metal cations $\left(\mathrm{Ba}^{2+}\right.$, $\mathrm{Mg}^{2+}$, and $\mathrm{Sr}^{2+}$ ) did not influence $\mathrm{CoQ} 1$ electrochemistry.

A different behavior was found when $\mathrm{CoQ} 1$ was dissolved in strong alkaline media $(0.1 \mathrm{M} \mathrm{NaOH})$. CVs recorded at different times after dissolving $\mathrm{CoQ} 1$ in $0.1 \mathrm{M} \mathrm{NaOH}$ (Figure 1A) revealed two chemically reversible and time-dependent redox 
processes. While the peak-currents of the first pair of peaks at more positive potentials decrease with time, the second pair of peaks at more negative potentials increases concomitantly (Figure 1A). After $8 \mathrm{~h}$ in $0.1 \mathrm{M} \mathrm{NaOH}$, the first voltammetric redox process of CoQ1 is hardly visible, while the peak current of the second redox process at more negative potentials showed a pronounced intensity (bottom right panel in Figure 1A). Because the decrease (or increase) of both anodic and cathodic peakcurrents is related to a decrease (or increase) in concentration of electroactive species, the voltammograms suggest formation of a product with redox properties distinct from the native CoQ1. Additionally, a chemical reaction between CoQ1 and hydroxide ions $\left(\mathrm{OH}^{-}\right)$and formation of a new product is evident from the color conversion from yellowish via bright red to purple (Figure $\mathrm{S} 1 \mathrm{~A}$, right snapshot). After $8 \mathrm{~h}$, the new product, associated with the redox process at more negative potentials, represents the predominant fraction in the solution. Once being formed in the strong alkaline solutions, the product appears to be rather stable upon retitration to neutral or acidic $\mathrm{pH}$. A comparison between the CVs of the native CoQ1 (black trace) with the chemically transformed CoQ1 (red trace) is shown in Figure 1B. In both cases, the $\mathrm{pH}$ of the solution was adjusted to 7.4 to mimic physiological conditions. The midpeak potential, which is related to thermodynamic features of the redox process, differs significantly between the two voltammograms, which implies that they originate from two different CoQ1-like species. In addition, the product formed by the reaction between $\mathrm{CoQ} 1$ and $\mathrm{NaOH}$ shows an increased solubility in $\mathrm{H}_{2} \mathrm{O}$, thus indicating a change in the hydrophilic properties of the new molecular form.

To further confirm the chemical reactions and the structural changes of CoQ1 in strong alkaline solutions, we performed $\mathrm{UV}$ - vis measurements. Adding $0.1 \mathrm{M} \mathrm{NaOH}$ to the CoQ1 solution revealed clear time-dependent changes in the absorption bands, which are related to the formation of the new compound (Figure 1C). The initial UV-vis spectrum ( $5 \mathrm{~min}$ ) consists of two absorption bands located at $\sim 280$ and $\sim 325 \mathrm{~nm}$, and the absorption band of the aromatic ring at $\sim 220 \mathrm{~nm}$ (Figure 1C, see also ref 38 ). Similar to the voltammetric measurements, the absorption band of the native CoQ1 decreases over time, while the intensity of the second band at $325 \mathrm{~nm}$ continuously increases. After a period of $3.5 \mathrm{~h}$, the chemical equilibrium is significantly shifted toward the product of the chemical reaction, yielding a broad absorption peak at $325 \mathrm{~nm}$ (red curve in Figure $1 \mathrm{C}$ ). In comparison, the native $\mathrm{CoQ} 1$ in neutral $\mathrm{H}_{2} \mathrm{O}$ solution shows only a single absorption band at $\sim 280 \mathrm{~nm}$ (apart from the $220 \mathrm{~nm}$ band) (Figure S1E). Hence, the band at $280 \mathrm{~nm}$ in Figure $1 \mathrm{C}$ is correlated with the native form of CoQ1, while the band at $325 \mathrm{~nm}$ arises from absorption of the product created in the reaction of $\mathrm{CoQ} 1$ and $\mathrm{NaOH}$.

Tracking the Reaction Mechanism of CoQ1 in Alkaline Medium. In alkaline conditions, benzoquinones with at least one unsubstituted site in the aromatic ring form dianions as intermediates with reducing properties after $\mathrm{OH}^{-}$attack. ${ }^{33}$ To identify the structure of the new product, and to gain more insight into the chemical reaction between $\mathrm{CoQ} 1$ and $\mathrm{NaOH}$, we performed electron paramagnetic (EPR) and nuclear magnetic resonance (NMR) measurements after dissolving CoQ1 in aqueous solutions with different $\mathrm{pH}$ values.

As expected, in neutral and acidic $\mathrm{pH}$ we did not observe spontaneous radical formation. However, addition of the reducing agent sodium borhydride, $\mathrm{NaBH}_{4}$, induced a specific 9-line EPR-spectrum in neutral media (Figure $2 \mathrm{~A}$, red trace), which
A
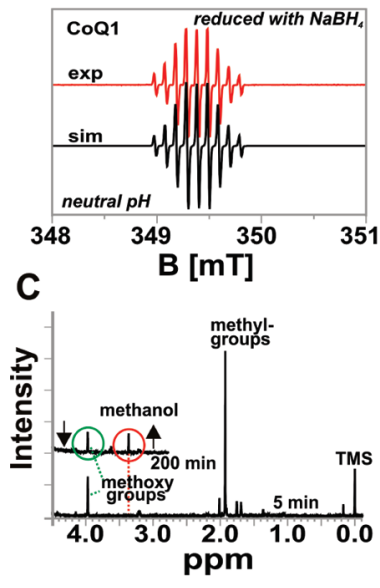

B

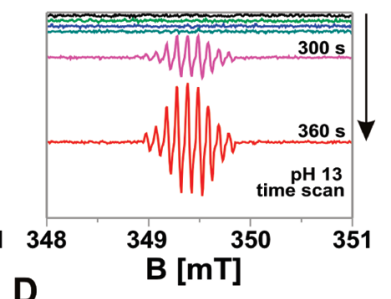

D

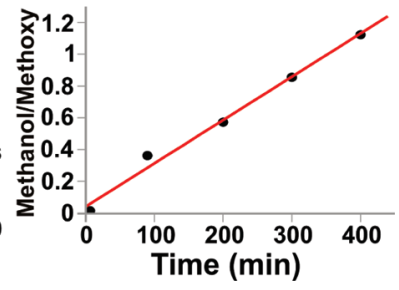

Figure 2. Determining the structure of the new CoQ1 product using EPR and NMR. (A) EPR spectrum of $0.5 \mathrm{mM} \mathrm{CoQ} 1$ recorded in neutral $\mathrm{pH}(\sim 7)$, in the presence of half-equivalent molar amount of $\mathrm{NaBH}_{4}$. $\exp =$ experimental, $\operatorname{sim}=$ simulated $\left(3 \mathrm{H}\right.$ of methyl $a_{\text {iso }}=0.203 \mathrm{mT} ; 2$ equiv $\mathrm{H}$ of isoprenoid chain $a_{\text {iso }}=0.103 \mathrm{mT}$, line width $(\mathrm{LW})=0.018$ $\mathrm{mT}$. (B) EPR spectra of $4 \mathrm{mM} \mathrm{CoQ} 1$ recorded in $0.1 \mathrm{M} \mathrm{NaOH}$. (C) NMR spectra of $1 \mathrm{mg} / \mathrm{mL}$ CoQ1 dissolved in $0.1 \mathrm{M} \mathrm{NaOD}$ for different times, and retitrated to $\mathrm{pD}$ of $\sim 7$ with $\mathrm{DNO}_{3}$. TMS = tetramethyl silane. (D) Ratio of the relative integrals from the signal of methanol and methoxy groups as a function of time. TMS was used as an internal standard. The ratio is measured from the NMR spectra of $1 \mathrm{mg} / \mathrm{mL}$ $\mathrm{CoQ} 1$ dissolved in $0.1 \mathrm{M} \mathrm{NaOD}$ for different times, and retitrated to $\mathrm{pD}$ of 7 with $\mathrm{DNO}_{3}$.

could be fully simulated by the interaction of one $\mathrm{CH}_{3}$ and one $\mathrm{CH}_{2}$ group (Figure 2A, black trace). Because of the intrinsic asymmetry of $\mathrm{CoQ} 1$, the $\mathrm{CH}_{3}$-protons of the methoxy-group(s) have rather small couplings that were not resolved in the EPR spectra. ${ }^{39,40}$ In strong alkaline solutions $(0.1 \mathrm{M} \mathrm{NaOH})$, but in the absence of a reducing agent, an identical 9-line spectrum appeared. This radical signal showed a pronounced time dependence, with increasing intensity (i.e., radical concentration) after a short lag time ( $\sim 5 \mathrm{~min}$ at $\mathrm{pH}$ of 13 ) (Figure $2 \mathrm{~B}$ ) for about $2 \mathrm{~h}$, and was stable for several hours afterward. This finding differs from the present knowledge about radical chemistry of various benzoquinones. Tetra-substituted benzoquinones with alkyl substituents should not form radicals in basic media, because the addition of $\mathrm{OH}^{-}$as a crucial step to produce a dianion should not occur. ${ }^{41,42}$ This step is thought to be a prerequisite for electron transfer from a dianion intermediate to the native compound, which constitutes the primary observed EPR radical signal (see Scheme 2). However, all four ring positions of CoQ1 are occupied with methoxy, methyl, or alkyl groups. To resolve this discrepancy, we tested if some of the above-mentioned groups are cleaved by $\mathrm{NaOH}$, thus allowing radical formation. For this purpose, 2-methyl benzoquinone (2-MBQ), a derivative containing only one methyl group in its structure, was dissolved in highly alkaline solutions in the same way as CoQ1. The possible cleavage of the only methyl group should consequently result in the loss of the methyl group signal in the EPR spectrum. As expected, in highly alkaline solutions, 2-MBQ radicals were detected, but always contained a methyl group, indicating that no methyl bond cleavage occurred. ${ }^{41,43}$ Additional evidence for the stability of the methyl groups substituted in the quinone structure was obtained from experiments with $1 \mathrm{mM}$ duroquinone 
Scheme 2. Proposed Transformation Pathway of CoQ1 in Alkaline Media ${ }^{a}$

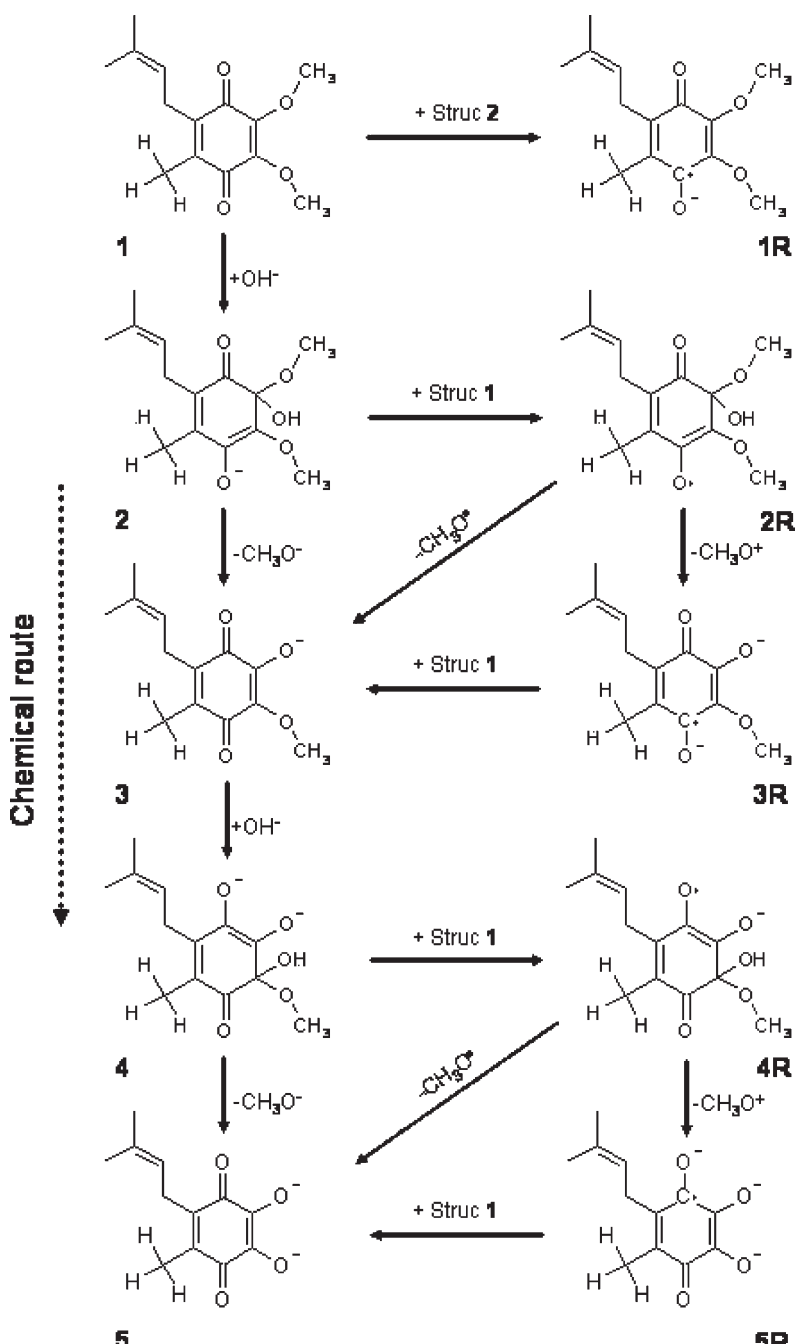

$\mathbf{5 R}$

${ }^{a}$ On the left side, the possible non-radical structures of the reaction of $\mathrm{CoQ} 1$ (structure $\mathbf{1}$ ) toward the di-hydroxylated CoQ1 (structure 5) are displayed; on the right, the radical structures $(\mathrm{R})$ are shown. The initial attachment of the $\mathrm{OH}^{-}$to the CoQ1 molecule results in the formation of a monoanion hydroxyl intermediate (2), which is readily transformed to a di-anionic form, due to dissociation of the attached hydroxyl group. The di-anion intermediate, with a disturbed quinone-like structure, has a strong reducing ability, expelling one electron to the parent CoQ1 molecule to form $\mathbf{1 R}$. The structure $\mathbf{2 R}$ is again a radical, but could not be observed clearly in EPR, most likely because of its short life time. The following transformation involves loss of a methoxy group (charged or as radical) leading to structures 3 and $3 R$. The hydroxylation reaction can occur a second time, yielding an intermediate di-anion and its radical, 4 and $\mathbf{4 R}$, which is finally converted to the di-hydroxylated form of CoQ1 $(5,5 R)$. Experimentally, there are at least two more radical spectra appearing in a time period up to $9 \mathrm{~h}$, one of which is visible roughly in parallel to the "native" 9-line spectrum. Both radical species consist of a $3 \mathrm{H}$ methyl- and two nearly equivalent $2 \mathrm{H}$ hyperfine couplings. According to the reaction scheme, these species may be related to the structures $3 \mathbf{R}$ and $\mathbf{5 R}$. This quite complex kinetic radical behavior also shows a dependence on $\mathrm{pH}$ and will be analyzed in more detail.

(tetramethyl benzoquinone), which possess $\mathrm{CH}_{3}$ groups at positions 2, 3, 5, and 6 in the aromatic ring. Even after prolonged
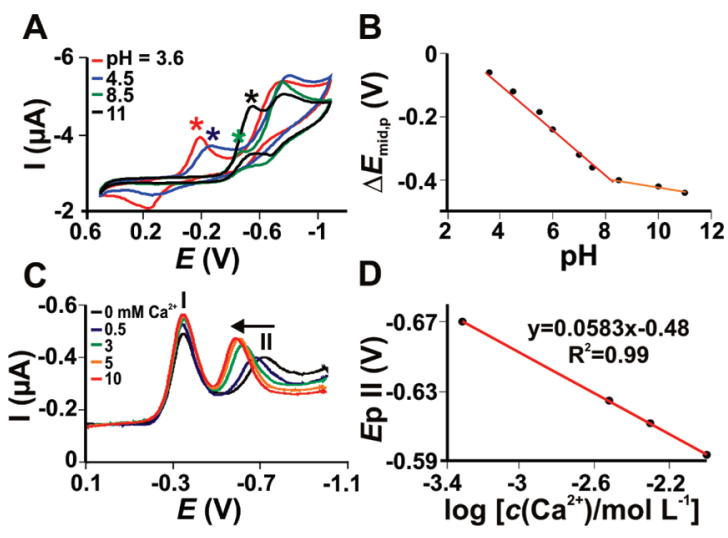

Figure 3. Hydroxyl CoQ1 binds $\mathrm{Ca}^{2+}$ and is less $\mathrm{pH}$ sensitive. (A) CVs of $50 \mu \mathrm{M} \mathrm{CoQ} 1$ (dissolved in $0.1 \mathrm{M} \mathrm{NaOH}$ for $60 \mathrm{~min}$ and retitrated to $\mathrm{pH}$ of 7) as a function of $\mathrm{pH}$. Scan rate $=30 \mathrm{mV} / \mathrm{s}$. (B) Midpeak potential dependence on $\mathrm{pH}$ for the response of the peak assigned to the native CoQ1 appearing at more positive potentials (see panel A, marked with asterisks). (C) Net square-wave voltammograms showing the $\mathrm{Ca}^{2+}$-sensitivity of the redox process of the hydroxylated form of CoQ1 (peak II). $c(\mathrm{CoQ} 1)$ was $10 \mu \mathrm{M}, \mathrm{pH} \approx 7.4$. SW frequency $f=$ $8 \mathrm{~Hz}$, SW amplitude $E_{\mathrm{sw}}=50 \mathrm{mV}$, and potential step dE $=1 \mathrm{mV}$. (D) Net SWV peak potential dependence on logarithm of $\mathrm{Ca}^{2+}$ concentration for the response of the hydroxylated form of CoQ1 (peak II in panel C).

exposure (up to several weeks) of duroquinone in $1 \mathrm{M} \mathrm{NaOH}$, no increased solubility was observed. Having clear evidence that ring constituents such as methyl or isoprenoid groups are not cleaved under alkaline conditions, only a nucleophilic attack at the methoxy groups remains as a possibility to explain the new structures observed in the electrochemical and EPR measurements. Because of the polarization of the carbon ring, nucleophilic substitution appears to be the plausible pathway (see Scheme 2). In such a case, methanol would be expected to be produced in the solution. We tested that prediction using nuclear magnetic resonance (NMR) measurements. CoQ1 was dissolved in $1 \mathrm{M} \mathrm{NaOD}$ for defined times, and then retitrated to neutral $\mathrm{pD}$ with $\mathrm{DNO}_{3}$ to quench the reaction. The NMR spectra (Figure 2C) of CoQ1 dissolved in $\mathrm{NaOD}$ at 5 min (lower trace) and at $200 \mathrm{~min}$ (upper trace) clearly show a decay of the methoxy group signals (green circle) with time, while a new signal for methanol (red circle) appears, both signals being strictly correlated over several hours (Figure 2D). These findings provide strong evidence that the loss of the methoxy groups of CoQ1 leads to the generation of a new hydroxylated product, which exists in an anionic form in basic medium (Scheme 2, structures 3 and 5, and refs 44,45 ). This derivative can exist as a mono- or dianion, which is the main reason for its highly increased water solubility. The color of hydroxyl quinone derivatives is a very helpful indicator to distinguish between mono- and dihydroxyl quinones. While the water solutions $(\mathrm{pH} \approx 7)$ of the dihydroxy quinones (which exist in double dissociated form in neutral media) have a reddish color (Figure S2A, left), the monohydroxy quinones (which exist in a mono dissociated form) in neutral media have a yellowish color (Figure S2A, right). Obviously, the color of the new hydroxylated CoQ1 (Figure S2A, middle) is quite similar to that of the dihydroxyl benzoquinone. In summary, the new forms obtained via a chemical reaction of $\mathrm{CoQ} 1$ with $\mathrm{OH}^{-}$in $\mathrm{pH}$ of 13 can be either double dissociated 2,3-dihydroxyl-5-methyl-6-isoprenyl benzoquinone (dihydroxyl CoQ1) or a monohydroxyl CoQ1. The presence of dissociable hydroxyl groups in the structures of 
Scheme 3. $\mathrm{Ca}^{2+}$ Binding by Mono- and Di-hydroxylated CoQ1 ${ }^{a}$<smiles>[R]c1c(C)c(OC)c(OC)c(OC)c1O[Ge]</smiles>

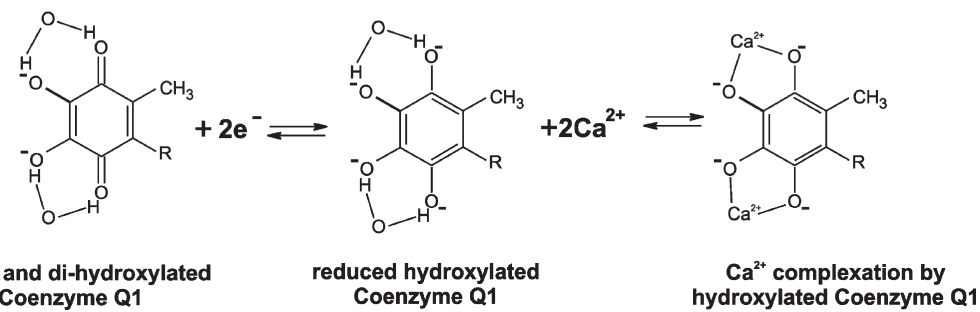

${ }^{a}$ Mono (upper row)- and di (lower row)-hydroxylated CoQ1 are reduced and immediately hydrated. Water molecules are replaced by $\mathrm{Ca}^{2+}$ ions, leading to the formation of $\mathrm{Ca}^{2+}: \mathrm{CoQ} 1$ complexes with stoichiometry of $1: 1$ or 2:1.

these new hydroxyl CoQ derivatives should change their chemical properties with respect to the native compounds. This was tested in the next set of experiments.

Proton Insensitivity and $\mathrm{Ca}^{2+}$ Sensitivity of Hydroxylated CoQ1 Derivative(s). First, we analyzed the redox properties of the new hydroxylated derivatives of $\mathrm{CoQ} 1$. The $\mathrm{pH}$-dependence in a range from $\mathrm{pH} 3.6$ to 11 shows two redox processes in the CVs (Figure 3A): a proton-sensitive process at more positive potentials (i.e., its midpeak potential shifts for $60 \mathrm{mV} / \mathrm{pH}$, Figure 3B, marked with asterisks in Figure 3A) originating from the native form of CoQ1, and a second redox process at more negative potentials (assigned to the hydroxylated derivative), which is insensitive to proton concentration in the considered $\mathrm{pH}$ region. This is a quite unusual finding, because the redox chemistry of most quinones is generally $\mathrm{pH}$ sensitive. ${ }^{16}$ The rather negative potential needed to reduce this product is, however, consistent with the considerable electronic density present in its structure (see Scheme 2). In addition, the virtually constant midpeak potential of the new hydroxyl CoQ1 (second redox process) in the $\mathrm{pH}$ range 3.6-11 implies significant acidic properties of this hydroxylated derivative and is indicative for the presence of strong hydrogen bonds with solvent molecules, as recently proposed in ref 37 .

Above all, the most intriguing feature of the hydroxylated product is its ability to form complexes with $\mathrm{Ca}^{2+}$ ions (Figure 3C), and to some extent with other earth-alkaline cations such as $\mathrm{Ba}^{2+}$ and $\mathrm{Mg}^{2+}$ (Figure S2B and C) in neutral or slightly acidic solutions. Besides cyclic voltammetry, the more advanced and sensitive square wave voltammetry was applied to record the evolution of the voltammetric response of the reaction mixture with increasing $\mathrm{Ca}^{2+}$ concentration (Figure 3C). While the reduction peak $\mathrm{I}$, which is associated with the native CoQ1 form, is virtually insensitive to $\mathrm{Ca}^{2+}$ ions, the reduction peak II, which is associated with the hydroxyl CoQ1, shifts toward more positive potentials with an increasing $\mathrm{Ca}^{2+}$ concentration. This shift reveals a redox switching complexation mechanism, in which the electrochemically reduced (quinol) form of the hydroxylated derivative is capable to complex $\mathrm{Ca}^{2+}$ ions. The slope of the linear dependence $\Delta E_{\mathrm{p} \text {,mid }}$ versus $\log \left[c\left(\mathrm{Ca}^{2+}\right)\right]$ has a thermodynamic value of $\sim 59 \mathrm{mV}$ (Figure $3 \mathrm{D}$ ), implying an equal number of electrons exchanged in the electrode reaction with the number of $\mathrm{Ca}^{2+}$ ions participating in the complexation reaction. The interception of the $E_{\mathrm{p}}$ versus $\log \left[c\left(\mathrm{Ca}^{2+}\right)\right]$ plot indicates a dissociation constant $\left(K_{\mathrm{d}}\right)$ of the $\mathrm{CoQ}-\mathrm{Ca}^{2+}$ complex with a value around $\sim 150 \mathrm{nM}^{2}$.

Yet, the stoichiometry of the complex cannot be unambiguously determined from the electrochemical measurements, due to the complexity of the electrode reaction of CoQs, which can often proceed via formation of a semiquinone form. Hence, besides the 1:2 ( $\mathrm{CoQ}: \mathrm{Ca}^{2+}$ ) complex with the hydroquinone (quinol) forms of hydroxyl derivatives of both CoQ1 and CoQ10, the possibility of 1:1 complex with the semiquinone (semiquinol) forms cannot be excluded (Scheme 3).

Properties of CoQ10 in the Presence of $\mathrm{NaOH}$ or Cytochrome P450. The very low solubility of CoQ10 in water is the main obstacle to perform electrochemical experiments from a dissolved state in aqueous media. However, CoQ10 dissolves slowly in $1 \mathrm{M} \mathrm{NaOH}$ in micromolar concentrations. The voltammetric behavior of a neutralized solution of CoQ10 resembles that of CoQ1 already described in the previous sections, also showing two redox processes at distinct potentials (Figure 4A).

From a physiological point of view, it was particularly important to investigate if similar structural changes of CoQ10 can be induced by enzymatic reactions. Cytochrome P450 (CYP450) monoxygenases are involved in the conversion of a variety of substrates by catalyzing diverse reactions, such as cleaving of $\mathrm{C}-\mathrm{C}$ or $\mathrm{C}-\mathrm{O}$ bonds. ${ }^{46-48}$ In humans, CYP450s are usually present together with $\mathrm{CoQ} 10$ in the inner mitochondrial membrane or in the membranes of the endoplasmic reticulum. To test if CYP450 could induce an enzymatic reaction as shown for other quinones, ${ }^{49} \mathrm{CoQ} 10$ was added to an aqueous solution ( $\mathrm{pH} 7.4$ ) containing CYP4501B1 (together with NADPH-P450 reductase). Voltammetric measurements are only possible if a substantial amount of CoQ10 undergoes structural changes (i.e., hydroxylation), thereby increasing solubility. In the $\mathrm{CV}$, two well-developed voltammetric peaks with distinct midpoint potential were obtained (Figure 4B) after a prolonged exposure of CoQ10 to CYP450B1, showing a CV very similar to that found after exposure to alkaline solution (Figure 4A). Analogous to CoQ1 (Figure 3C), the square wave voltammogram (SWV) peak positioned at more negative potential (II) is strongly sensitive to $\mathrm{Ca}^{2+}$ ions, whereas the position of the peak at more positive potential (I) is independent of the $\mathrm{Ca}^{2+}$ concentration (Figure 4C). As depicted in Figure 4D, the slope of the linear dependence 

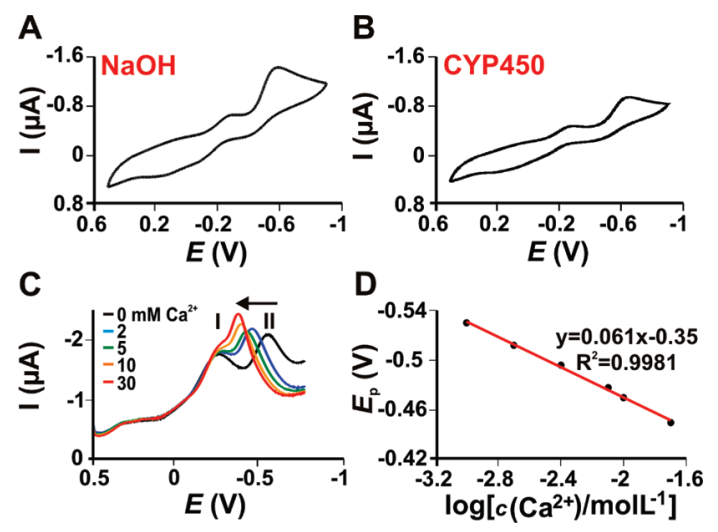

Figure 4. CYP450 induces structural changes of CoQ10 and renders it sensitive to $\mathrm{Ca}^{2+}$. (A) CVs of $2 \mu \mathrm{M}$ CoQ10 recorded in aqueous solution $(\mathrm{pH} \approx 7.4)$ after prolonged exposure to $1 \mathrm{M} \mathrm{NaOH}$. (B) $\mathrm{CV}$ of $2 \mu \mathrm{M} \mathrm{CoQ} 10$ in aqueous solution $(\mathrm{pH} \approx 7.4)$ after prolonged exposure to $1 \mathrm{nM}$ Cytochrome P450 (CYP450). (C) The effect of different $\mathrm{Ca}^{2+}$ concentrations on the net SWVs of CoQ10 previously exposed to $1 \mathrm{nM}$ $\mathrm{CYP} 450 . \mathrm{pH} \approx 7.40$. The parameters of the potential modulation are the same as in Figure 3C. (D) Dependence of the net SW peak potential of CoQ10 previously exposed to $1 \mathrm{nM}$ CYP450 on the logarithm of $\mathrm{Ca}^{2+}$ concentration (peak II in panel C).

$E_{\mathrm{p}}(\mathrm{II})$ versus $\log \left[c\left(\mathrm{Ca}^{2+}\right)\right]$ has a value of $61 \mathrm{mV}$, implying an analogous complex formation mechanism as in the case of CoQ1. We conclude that an enzymatic reaction by CYP450 or strong alkaline solutions can induce structural changes in CoQ10 similar to CoQ1 and modify their chemical features, most importantly leading to $\mathrm{Ca}^{2+}$ complexation.

To determine if the hydroxylated form of CoQ10 not only binds $\mathrm{Ca}^{2+}$ but is also able to transport $\mathrm{Ca}^{2+}$ in a lipid environment, we applied cyclic and square wave voltammetry using thinorganic-film electrodes (see refs 29,30). An artificial membrane consisting of 1,2-dichlorethan (DCE) and phospholipids was immobilized on the surface of a graphite electrode. When CoQ10 is embedded in this membrane, the modified electrode gives rise to a well-developed voltammetric response associated with the quinone/quinol redox couple, being sensitive to the $\mathrm{pH}$ of the aqueous phase but insensitive to $\mathrm{Ca}^{2+}$ ions (Figure S3A and B). In the presence of tetraoctylammonium hydroxide $\left(\mathrm{Oct}_{4} \mathrm{~N}(\mathrm{OH})\right)$ in the organic membrane (added as a hydroxyl donating reactant), however, a reaction is induced, which causes a change of the color from yellow to red-brown (Figure S3C), analogous to CoQ1 (Figure S1A).

The voltammetric measurements performed in aqueous solutions containing various amounts of $\mathrm{Ca}^{2+}$ (Figure 5A) indicate that the quinol form of the hydroxylated derivative of CoQ10 is capable to bind $\mathrm{Ca}^{2+}$ at the membrane-water interface, and to facilitate the $\mathrm{Ca}^{2+}$ transport into the membrane interior. This is reflected by the thermodynamic shift of the CVs cathodic-peak potentials depending on $\mathrm{Ca}^{2+}$ concentrations with a slope of 54 $\mathrm{mV} / \log \left[c\left(\mathrm{Ca}^{2+}\right)\right]$ (Figure 5B).

To further test the hypothesis that hydroxyl CoQs are able to transport $\mathrm{Ca}^{2+}$, we combined the thin-organic-film setup with fluorescence-based $\mathrm{Ca}^{2+}$ imaging experiments. CoQ10 $(1 \mathrm{mM})$ was dissolved in the organic solvent NPOE in the presence of $\mathrm{Oct}_{4} \mathrm{~N}(\mathrm{OH})$ and phospholipids. A drop of the mixture was attached on a graphite electrode, which was submerged in aqueous solution containing $100 \mathrm{mM} \mathrm{Ca}^{2+}$. Application of a constant negative potential of $-0.6 \mathrm{~V}$ for $60 \mathrm{~min}$ was used to

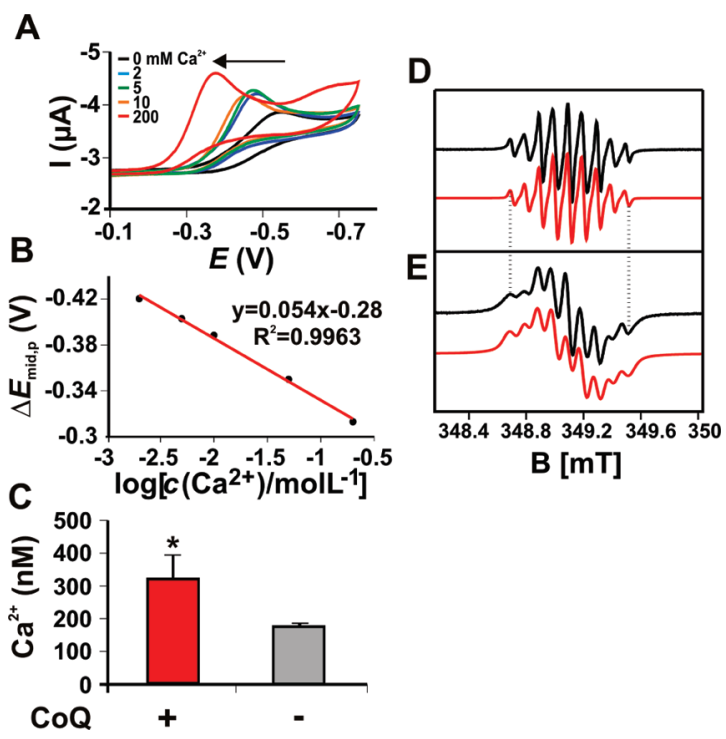

Figure 5. Hydroxyl CoQ10 transports $\mathrm{Ca}^{2+}$ across artificial biomembranes. (A) Thin-organic film electrode set up. CVs representing transfer of $\mathrm{Ca}^{2+}$ across an artificial biomimetic membrane facilitated by reduction of the embedded hydroxylated form of CoQ10. $100 \mu \mathrm{M}$ CoQ10 was initially dissolved in DCE containing $200 \mu \mathrm{M}$ tetraoctylammonium hydroxide and $100 \mu \mathrm{M}$ phosphatidyle choline. (B) Dependence of the cathodic-peak potential on the logarithm of $\mathrm{Ca}^{2+}$ concentration in the aqueous phase for the CVs shown in panel $\mathrm{A}$. (C) Fura 2 measurements of $\mathrm{Ca}^{2+}$ transported across hydroxyl CoQ enriched artificial biomembranes. $\mathrm{Ca}^{2+}$ concentration in the presence of $1 \mathrm{mM}$ CoQ10 (red bar) in the organic solvent was $\sim 319 \pm 73 \mathrm{nM}$, while in the absence of CoQ10 it was $175 \pm 3 \mathrm{nM}$. Error bars show standard deviation. $n=3$. Unpaired Student's $t$ test, $p=0.02$. (D) EPR spectra of $0.5 \mathrm{mM}$ CoQ10 recorded in tert-butylalcohol in the presence of halfequimolar amounts of tert-butylammonium chloride as reducing agent. (Simulation parameters: $3 \mathrm{H} 0.213 \mathrm{mT}, 1 \mathrm{Ha} 0.102 \mathrm{mT}, 1 \mathrm{Hb} 0.112 \mathrm{mT}$, LW $0.033 \mathrm{mT}$.) (E) EPR spectra of $0.5 \mathrm{mM} \mathrm{CoQ} 10$ recorded in tertbutylalcohol in the presence of $5 \mathrm{mM}$ organic base (tetraoctylammonium hydroxide) without any reductive agent. (Simulation parameters: $3 \mathrm{H} 0.203 \mathrm{mT}, 1 \mathrm{Ha} 0.100 \mathrm{mT}, 1 \mathrm{Hb} 0.104 \mathrm{mT}$, LW $0.095 \mathrm{mT}$.) The simulated curves are shown in red; the dotted lines indicate the position of the outer lines of the spectra.

reduce the hydroxyl CoQs and to induce a driving force for $\mathrm{Ca}^{2+}$ across the membrane interface. Under these conditions, according to our voltammetric measurements, the reduced hydroxyl CoQs bind and transfer $\mathrm{Ca}^{2+}$ ions into the organic solvent. This was tested by detaching the NPOE-CoQ10 mixture from the graphite electrode and solving it in $500 \mu \mathrm{L}$ of nominally $\mathrm{Ca}^{2+}$ free $\mathrm{H}_{2} \mathrm{O}$. Here, hydroxyl CoQ10 is oxidized by the oxygen present in the water and should release the bound $\mathrm{Ca}^{2+}$ ions. The $\mathrm{Ca}^{2+}$ concentration of the solution, in which NPOE+CoQ10 was stripped, was measured with fluorescence imaging technology using Fura 2 as a $\mathrm{Ca}^{2+}$ indicator. Identical conditions in the absence of CoQ10 served as control. Figure 5C shows that the $\mathrm{Ca}^{2+}$ concentration is increased from $\sim 175$ to $\sim 319 \mathrm{nM}$ in the presence of CoQ10. This increase depends on the amount of nominally $\mathrm{Ca}^{2+}$ free water $(500 \mu \mathrm{L})$ and would be much higher in smaller volumes as for instance in cells. These experiments further strengthen our conclusion that hydroxyl CoQs not only bind but also transport $\mathrm{Ca}^{2+}$ across artificial membranes.

In analogy to the EPR experiments of CoQ1, we also tried to verify the formation of the native $\mathrm{CoQ} 10$ radical via reduction by the dianionic intermediate species formed upon attack of $\mathrm{OH}^{-}$. 
Initially, a stable "native" CoQ10 radical was obtained in a solution of tert-butylalcohol by reduction with tert-butylammonium chloride, yielding the characteristic 9-line EPR signal also observed for the CoQ1 radical. It is simulated with almost identical parameters as for CoQ1 with a methyl group and now two slightly nonequivalent protons (Figure 5D). The methyl proton interactions of the methoxy group are not resolvable within the line width as was already the case for CoQ1. In a second experiment, the $\mathrm{OH}^{-}$donor tetraoctylammonium hydroxide was added to a solution of CoQ10 in tert-butylalcohol, which produced the radical signal presented in Figure 5E. This spectrum is reasonably well simulated by using nearly identical proton couplings but a 3-fold increased line width, which is probably related to a somewhat altered dynamic behavior of the radicals. In summary, the voltammetric and EPR-spectroscopic experiments provide clear evidence that in the presence of hydroxyde anions the hydroxyl derivatives of both CoQ1 and CoQ10 are formed, exhibiting distinct redox and $\mathrm{Ca}^{2+}$-handling properties.

Detection and Characterization of the Reaction Products between $\mathrm{CoQ} 1$ and $\mathrm{NaOH} / \mathrm{CYP} 450$ by HPLC-MS. To test the hypothesis that $\mathrm{NaOH}$ and $\mathrm{CYP} 450$ have a similar effect on the CoQ structure, we compared the products obtained from the exposure of CoQ1 to $\mathrm{NaOH}$ or to CYP450 by using HPLC-MS. In both cases, the components of the reactions were separated on a reversed phase $(\mathrm{C} 18)$ column. Three peaks were detected in the $\mathrm{CoQ} 1$ samples treated either with $\mathrm{NaOH}$ (Figure 6A, black line) or with CYP450 (Figure 6A, red line) at the same elution times (the black curve is shifted to the right for clarity). The identity of the species responsible for these three peaks was determined by their mass spectra obtained with electrospray ionization in the positive mode (Figures $6 \mathrm{~B}-\mathrm{G}$ ). The peak at $18.2 \mathrm{~min}$ is associated with unmodified CoQ1 by its mass $(m / z 251)$, retention time, and UV-vis spectra from a comparison with a standard CoQ1 sample. The fragmentation pattern of this peak shows molecular ions $[\mathrm{M}+\mathrm{H}]^{+}$at $\mathrm{m} / z 251$ and $[\mathrm{M}+\mathrm{Na}]^{+}$at $m / z 273$ indicative of the presence of native CoQ1 in $\mathrm{NaOH}$ (Figure 6B, top) and CYP450 samples (Figure 6E, top). After $\mathrm{MS}^{2}$ fragmentation of the molecular ion $[\mathrm{M}+\mathrm{H}]^{+}$, a base peak at $m / z 219[(\mathrm{M}+\mathrm{H})-32]^{+}$was observed, indicating a loss of $-\mathrm{OCH}_{3}$ moiety (Figure 6B,E, bottom). From the second peak at $14.8 \mathrm{~min}$, a molecular ion $[\mathrm{M}+\mathrm{H}]^{+}$was found at $m / z 237$ and $[\mathrm{M}+\mathrm{Na}]^{+}$at $m / z 259$ (Figure 6C,F, top), which corresponds to a molecular weight reduction of 14 units (one $\mathrm{CH}_{2}$ group) as compared to the mass of native CoQ1. This implies a substitution of one $-\mathrm{OCH}_{3}$ group with an $-\mathrm{OH}$ group. The $\mathrm{MS}^{2}$ fragmentation of the $[\mathrm{M}+\mathrm{H}]^{+}$molecular ion indicates a loss of 18 units, yielding a base peak at $\mathrm{m} / z 219$ $[(\mathrm{M}+\mathrm{H})-18]^{+}$due to loss of $\mathrm{H}_{2} \mathrm{O}$ (characteristic loss for $-\mathrm{OH}$ group containing ions) (Figure $6 \mathrm{C}, \mathrm{F}$, bottom). The additional peak at $m / z 205$ corresponds to a loss of $-\mathrm{OCH}_{3}$ moiety producing $[(\mathrm{M}+\mathrm{H})-32]^{+}$, analogous to the $m / z 219$ signal of the 18.2 min HPLC peak (see Figure 6B,E, bottom). The mass spectrum of the chromatographic peak with lowest intensity (at $5.1 \mathrm{~min}$ ) showed a molecular ion $[\mathrm{M}+\mathrm{H}]^{+}$at $m / z$ 223 (Figure 6D,G, top) corresponding to a molecular weight reduced by 14 units $\left(\mathrm{CH}_{2}\right)$ as compared to the previous monohydroxylated compound $(\mathrm{m} / z 237)$ and by 28 units (two $\left.\mathrm{CH}_{2}\right)$ as compared to the native compound $(\mathrm{m} / z 251)$. The considerable intensity of the fragment at $m / z 205$ implies the presence of two - OH groups in the structure giving a stable fragment $\left[\mathrm{M}+\mathrm{H}-\mathrm{H}_{2} \mathrm{O}\right]^{+}$after loss of one $-\mathrm{OH}$ group (Figure 6D,G, bottom).
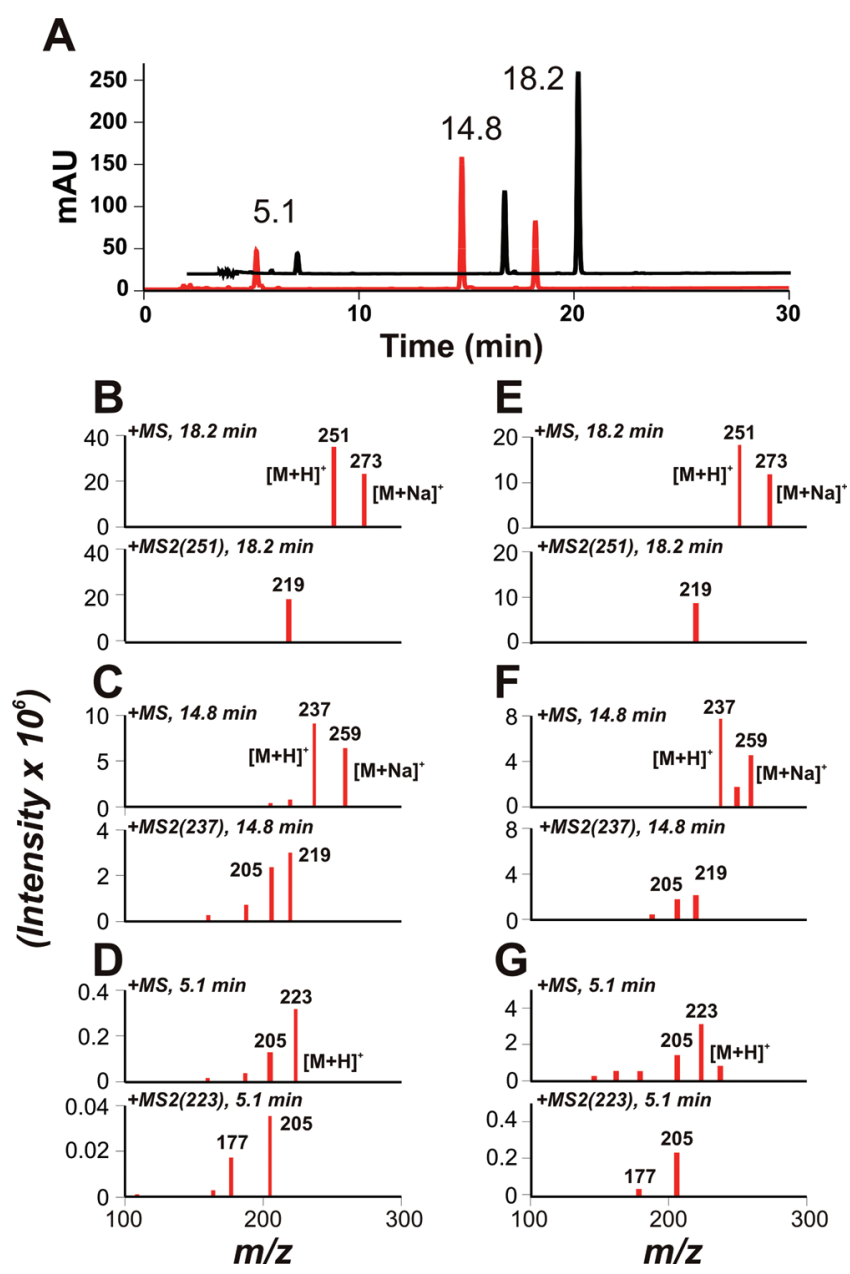

Figure 6. HPLC-MS spectra of CoQ1 treated with $\mathrm{NaOH}$ or CYP450. (A) Chromatograms of $0.8 \mathrm{mM} \mathrm{CoQ} 1$ treated with $0.1 \mathrm{NaOH}$ for $8 \mathrm{~h}$ and retitrated to $\mathrm{pH}$ of 7.4 (black), and of $0.8 \mathrm{mM} \mathrm{CoQ} 1$ in the presence of $1 \mathrm{nM}$ CYP450 (red). Mass spectra of native CoQ1 (B), monohydroxylated CoQ1 (C), and dihydroxylated CoQ1 (D) recorded from $0.8 \mathrm{mM} \mathrm{CoQ} 1$ treated with $0.1 \mathrm{M} \mathrm{NaOH}$ and retitrated to $\mathrm{pH}$ of 7.4. Mass spectra of native CoQ1 (E) monohydroxylated CoQ1 (F) and dihydroxylated CoQ1 $(\mathrm{H})$ recorded from $0.8 \mathrm{mM}$ CoQ1 exposed to CYP450 for prolonged time.

The molecular weights and the masses of the most abundant fragments in $\mathrm{MS}^{2}$ indicate the presence of three major compounds in both $\mathrm{NaOH}$ and CYP450 treated samples: (i) dimethoxy compound (native CoQ1, $[\mathrm{M}+\mathrm{H}]^{+}$at $m / z 251$ ) with base peak at $m / z 219$ after loss of one methoxy group, $[(\mathrm{M}+\mathrm{H})-32]^{+}$, (ii) monomethoxy monohydroxyl compound $\left([\mathrm{M}+\mathrm{H}]^{+}\right.$at $\left.m / z 237\right)$ with base peak at $m / z 219$ after loss of one hydroxyl group, $[(\mathrm{M}+\mathrm{H})-18]^{+}$, but also a peak with significant intensity at $m / z 205$ due to a loss of one methoxy group, $[(\mathrm{M}+\mathrm{H})-32]^{+}$, and (iii) dihydroxyl compound $([\mathrm{M}+$ $\mathrm{H}]^{+}$at $\left.m / z 223\right)$ with base peak at $m / z 205$ due to a loss of one hydroxyl group, $[(\mathrm{M}+\mathrm{H})-18]^{+}$.

In addition, the retention behavior also supports the identification of the three HPLC peaks. As expected, the most lipophilic native CoQ1 is eluted last (at $18.2 \mathrm{~min}$ ). The compound with one $-\mathrm{OCH}_{3}$ group substituted by $-\mathrm{OH}$ is eluted earlier (at $14.8 \mathrm{~min}$ ), while the disubstituted derivative, with two $-\mathrm{OH}$ groups as the most polar compound, is eluted first (at $5.1 \mathrm{~min}$ ) (see Figure 6A). 
In summary, the $\mathrm{HPLC}-\mathrm{MS}$ experiments confirm that $\mathrm{NaOH}$ and CYP450 have a similar effect on the CoQ structure. The dominating fractions in the solutions are mono- and dihydroxyl CoQ1. We conclude that both reactions induce the same products.

\section{DISCUSSION}

Considering the substituents at positions 2, $3\left(-\mathrm{O}-\mathrm{CH}_{3}\right), 5$ (isoprenoid chain), and $6\left(\mathrm{CH}_{3}\right)$ at the aromatic ring of CoQ1 and CoQ10, it is highly unlikely that these coenzymes could bind $\mathrm{Ca}^{2+}$ in a similar way than has been shown for $2 \mathrm{PHQ}$ due to the absence of the two adjacent oxygens that are present in 2PHQ (see ref 20). We confirmed that native CoQ1 and CoQ10 do not bind $\mathrm{Ca}^{2+}$. However, in alkaline media or following exposure to CYP450 enzymes, we observed structural changes and formation of hydroxylated derivatives of CoQ1 and CoQ10. The fact that similar hydroxylated forms are precursors of CoQ1 and CoQ10 during their biosynthesis adds to the physiological significance of our findings. ${ }^{6}$ These new hydroxyl derivatives of CoQ1 and CoQ10 have distinct chemical properties. They can complex and transfer $\mathrm{Ca}^{2+}$ across artificial biomembranes, have more negative reduction potentials than the native CoQs, and show a relatively $\mathrm{pH}$ insensitive redox chemistry.

The negative charges in the structures of the reduced hydroxyl CoQs (Scheme 3) are, indeed, necessary for complexing the small and strongly hydrated $\mathrm{Ca}^{2+}$ ions similarly to other $\mathrm{Ca}^{2+}$ chelators such as ethylenediaminetetraacetic acid (EDTA), ethyleneglycol tetraaceticacid (EGTA), and 1,2-bis(o-aminophenoxy)ethane- $N, N, N^{\prime}, N^{\prime}$-tetraaceticacid (BAPTA). EDTA, EGTA, and BAPTA contain four negative charges in neutral media, which are needed for strong electrostatic interactions with strongly hydrated $\mathrm{Ca}^{2+}$ ions. The $K_{\mathrm{d}}$ 's of the complex between EDTA (low $\mathrm{nM}$ range), EGTA ( $\mathrm{nM}$ and $\mu \mathrm{M}$ range), and BAPTA (nM range) with $\mathrm{Ca}^{2+}$ do not differ significantly from the one between hydroxylated $\mathrm{CoQ}$ with $\mathrm{Ca}^{2+}\left(150 \mathrm{nM}^{2}\right)$. The $K_{\mathrm{d}}$ value of the $\mathrm{CoQ}^{4-}-2 \mathrm{Ca}^{2+}$ complex could even be lower in the absence of the isoprenoid chain, which can cause steric constraints to the complexation sites of the hydroxylated CoQs due the folding effects in aqueous media. ${ }^{50,51}$ Correspondingly, we found that the CoQ10 analogue coenzyme Q0, which lacks the isoprenoid chain, has a $K_{d}$ for $\mathrm{Ca}^{2+}$ of $9.5 \mathrm{nM}^{2}$. On the other side, exactly this isoprenoid chain provides the hydroxylated CoQ10 with unique amphiphilic properties, which are of course not present in EDTA, EGTA, and BAPTA. This feature is of extreme importance for potential biological effects of hydroxylated CoQs. Using the lipophilic tail, the CoQs can incorporate into lipid membranes, while the hydrophilic quinone head is positioned outside of the lipids in the aqueous media. It is well-known that the quinone ring can flip from one to the other side of the membrane according to its redox state (charge). The reduced form will bind $\mathrm{Ca}^{2+}$, which will be released upon oxidation. This mechanism explains our finding that hydroxyl CoQs can transfer $\mathrm{Ca}^{2+}$ across biomimetic membranes (Scheme 4).

According to our electrochemical analysis, the difference between the midpeak potentials of the parent and the hydroxyl compound is $\sim 300 \mathrm{mV}$ for both CoQ1 and CoQ10. Because the standard redox potential is the main thermodynamic parameter determining the antioxidative ability of a given compound, it is obvious that the reduced forms of hydroxylated CoQs are much stronger antioxidants than the native ones.
Scheme 4. $\mathrm{Ca}^{2+}$ Transport by Hydroxyl CoQ across the Inner Mitochondrial Membrane ${ }^{a}$

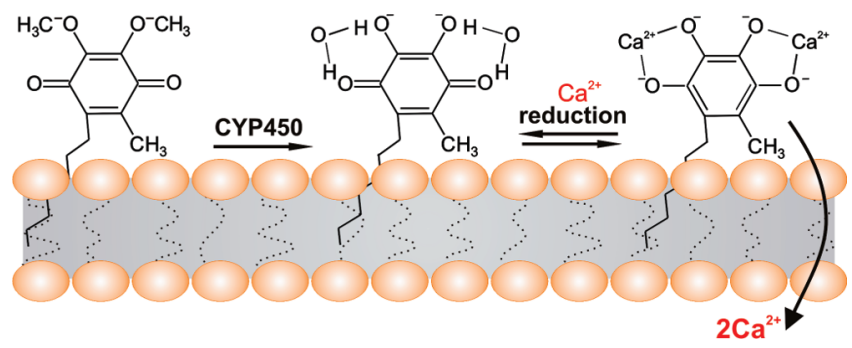

${ }^{a}$ Schematic presentation of the proposed model of $\mathrm{Ca}^{2+}$ transport across the IMM. CoQ10 is hydroxylated by the neighboring CYP450 enzymes and binds $\mathrm{Ca}^{2+}$ ions following its reduction. The associated oxidation of hydroxyl $\mathrm{CoQ}$ in the mitochondrial matrix leads to subsequent release of the $\mathrm{Ca}^{2+}$ ions.

There are several physiological implications of the novel chemical properties of the hydroxyl CoQs: (1) their strong antioxidative ability may contribute to eliminate reactive oxygen (ROS) species generated by mitochondria during oxidative phosphorylation, (2) they may modulate the rate of electron transfer along the ETC, (3) they may contribute to $\mathrm{Ca}^{2+}$ buffering, and (4) they may transport $\mathrm{Ca}^{2+}$ across biological membranes, in particular across the inner mitochondrial membrane.

(1) A recent paper ${ }^{52}$ indicates the importance of CoQ10 levels for cellular oxidative stress and cell viability. Considering the different redox properties of hydroxyl CoQ isoforms as compared to the native CoQs, it is plausible that their existence in the IMM should reduce mitochondrial ROS production and hence protect cells from their destructive effects. Through expression and localization of CYP450, cells could control the concentration of CoQ1/CoQ10 versus hydroxyl CoQs and could thereby control ROS production within mitochondria.

(2) It is plausible that the electron transport between the different complexes in the ETC is modulated and adapted to the needs of each particular cell type. The electron transfer rate in the ETC would affect the proton gradient across the IMM and ultimately the degree of ATP production. Again through the expression and localization of CYP450, cells could control the concentration of CoQ1/CoQ10 versus hydroxyl CoQs and thus their energy metabolism.

(3) The high affinity and high concentration of CoQ10 makes the hydroxyl CoQ10 an interesting candidate to buffer cytosolic $\mathrm{Ca}^{2+}$ levels close to the mitochondrial exterior. Interestingly, $\mathrm{Ca}^{2+}$ hot spots as a result of $\mathrm{Ca}^{2+}$ release from the endoplasmic reticulum have been recently discovered by Pozzan's group, ${ }^{53,54}$ indicating the importance to understand $\mathrm{Ca}^{2+}$ buffering mechanisms in the vicinity of the mitochondrial surface. A role of CoQ in $\mathrm{Ca}^{2+}$ buffering or transport is supported by findings that disturbed levels of $\mathrm{CoQ}$ induce a perturbed $\mathrm{Ca}^{2+}$ homeostasis. ${ }^{55,56}$ The high affinity of hydroxyl CoQ for $\mathrm{Ca}^{2+}$ enables it to contribute to the mitochondrial binding capacity even at low $(<0.5 \mu \mathrm{M})$ cytosolic $\mathrm{Ca}^{2+}$ concentrations. It is, however, difficult to estimate the $\mathrm{Ca}^{2+}$ binding capacity that hydroxyl CoQs add to the binding capacity of mitochondria. Assuming a cellular concentration of CoQ10 in the low millimolar range, ${ }^{6}$ a 
concentration of micromolar hydroxyl CoQ originating from both the biosynthesis of CoQ10 (hydroxyl quinones are precursors $)^{6}$ and the reaction with CYP450 appears reasonable. However, because we currently do not know the exact concentration of hydroxyl CoQs in cells, we cannot assign a $\mathrm{Ca}^{2+}$ buffering capacity for these quinone forms.

(4) Our results with the hydroxyl CoQs highlight their likely function for $\mathrm{Ca}^{2+}$ transport across biological membranes. Mitochondrial $\mathrm{Ca}^{2+}$ uptake is most prominent at cytosolic $\mathrm{Ca}^{2+}$ concentrations higher than $0.5 \mu \mathrm{M}$; it is drastically accelerated above $1 \mu \mathrm{M}$ and does not saturate readily. At lower cytosolic $\mathrm{Ca}^{2+}$ concentrations, mitochondrial $\mathrm{Ca}^{2+}$ accumulation is slow. The most prominent mode of $\mathrm{Ca}^{2+}$ uptake is mediated by the mitochondria $\mathrm{Ca}^{2+}$ uniporter (MCU), which is biophysically very well characterized and has a low affinity but high capacity, but whose molecular identity is still uncertain. ${ }^{25,26,57,58}$ Besides the MCU, other different modes of $\mathrm{Ca}^{2+}$ uptake of mitochondria have been described, rapid or slow, with high or low affinity and high or low capacity. ${ }^{25,26,57} \mathrm{~A}$ recent report based on genome wide siRNA screen identified a $1: 1 \mathrm{Ca}^{2+} / \mathrm{H}^{+}$exchanger protein named Letm1, which does not have all of the biophysical properties of MCU but may be involved in the slow $\mathrm{Ca}^{2+}$ uptake pathway. ${ }^{59}$ In addition, the uncoupling proteins 2 and 3 have been implicated in mitochondrial $\mathrm{Ca}^{2+}$ uptake, but their roles remain controversial. ${ }^{60}$ Our data indicate that hydroxyl CoQs are generated under physiological conditions and that they are able to bind and transport $\mathrm{Ca}^{2+}$ across artificial biomembranes. As compared to MCU, the mitochondrial $\mathrm{Ca}^{2+}$ accumulation mediated by hydroxyl CoQs is expected to be slower; however, the affinity is very high, and thus the transport is able to operate at cytosolic $\mathrm{Ca}^{2+}$ concentrations lower than $0.5 \mu \mathrm{M}$ and potentially even at resting $\mathrm{Ca}^{2+}$ levels.

In summary, the chemical features of hydroxyl CoQs establish the members of CoQ family as important players in the cellular $\mathrm{Ca}^{2+}$ homeostasis.

\section{ASSOCIATED CONTENT}

Supporting Information. Three supporting figures showing snapshots of the native CoQs and their derivatives and the sensitivity of their voltammetric responses toward $\mathrm{Ca}^{2+}$. This material is available free of charge via the Internet at http:// pubs.acs.org.

\section{AUTHOR INFORMATION}

\section{Corresponding Author}

markus.hoth@uks.eu; rubin.gulaboski@ugd.edu.mk

\section{Author Contributions}

"These authors contributed equally.

\section{ACKNOWLEDGMENT}

We are very grateful to Drs. B. Morgenstern and B. Kutzky for their help with the NMR experiments and to Dr. B. A. Niemeyer for critical reading of the manuscript. R.G. acknowledges the "Alexander von Humboldt" foundation for providing a postdoctoral and a Return Fellowship. This project was funded by the Deutsche Forschungsgemeinschaft (SFB 530, SFB 894, and the Graduate Research School GK845, to M.H.) and competitive research grants from the Saarland University (HOMFOR to I.B., R.K., and M.H.). This work is also supported by the Alexander von Humboldt Foundation via the joint German-Macedonian project from the Research Group Linkage Programme 3.4-FokoopDEU/1128670 (to V.M., R.G., I.B., and M.H.).

\section{REFERENCES}

(1) Lester, R. L.; Crane, F. L.; Hatefi, Y. J. Am. Chem. Soc. 1958, $80,4751-4752$.

(2) Lester, R. L.; Crane, F. L. J. Biol. Chem. 1959, 234, 2169-2175.

(3) Crane, F. L.; Hatefi, Y.; Lester, R. L.; Widmer, C. Biochim. Biophys. Acta 1957, 25, 220-221.

(4) Roetig, A.; Appelkvist, E.-L.; Geromel, V.; Chretien, D.; Kadhom, N.; Edery, P.; Lebideau, M.; Dallner, G.; Munnich, A.; Ernster, L.; Rustin, P. Lancet 2000, 356, 391-395.

(5) Crane, F. L. J. Am. Coll. Nutr. 2001, 20, 591-598.

(6) Turunen, M.; Olsson, J.; Dallner, G. Biochim. Biophys. Acta, Biomembr. 2004, 1660, 171-199.

(7) Lenaz, G.; Fato, R.; Formiggini, G.; Genova, M. L. Mitochondrion 2007, 7, S8-S33.

(8) Beyer, R. E. Free. Radical Biol. Med. 1990, 8, 545-565.

(9) James, A. M.; Smith, R. A. J.; Murphy, M. P. Arch. Biochem. Biophys. 2004, 423, 47-56.

(10) Kowaltowski, A. J.; Castilho, R. F.; Vercesi, A. E. Am. J. Physiol. 1995, 269, C141-C147.

(11) Swenton, J. Chemistry of Quinones; John Wiley: New York, 1988.

(12) Gordillo, G. J.; Schiffrin, D. J. J. Chem. Soc., Faraday Trans. 1994, 90, 1913-1922.

(13) Schrebler, R. S.; Arratia, A.; Sanchez, S.; Haun, M.; Duran, N. Bioelectrochem. Bioenerg. 1990, 23, 81-91.

(14) Takehara, K.; Takemura, H.; Ide, Y.; Okayama, S. J. Electroanal. Chem. 1991, 308, 345-350.

(15) Ksenzhek, O. S.; Petrova, S. A.; Kolodyazhny, M. V. Bioelectrochem. Bioenerg. 1982, 9, 167-174.

(16) Gordillo, G. J.; Schiffrin, D. J. Faraday Discuss 2000, 89-107; discussion 171-90.

(17) Moncelli, M. R.; Herrero, R.; Becucci, L.; Guidelli, R. Biochim. Biophys. Acta, Bioenerg. 1998, 1364, 373-384.

(18) Marchal, D.; Boireau, W.; Laval, J. M.; Moiroux, J.; Bourdillon, C. Biophys. J. 1998, 74, 1937-48.

(19) Bennett, I. M.; Farfano, H. M. V.; Bogani, F.; Primak, A.; Liddell, P. A.; Otero, L.; Sereno, L.; Silber, J. J.; Moore, A. L.; Moore, T. A.; Gust, D. Nature 2002, 420, 398-401.

(20) Mirceski, V.; Gulaboski, R.; Bogeski, I.; Hoth, M. J. Phys. Chem. C 2007, 111, 6068-6076.

(21) Rizzuto, R.; Bernardi, P.; Pozzan, T. J. Physiol. 2000, 529, $37-47$.

(22) Duchen, M. R. Cell Calcium 2000, 28, 339-348.

(23) Hajnóczky, G.; Robb-Gaspers, L. D.; Seitz, M. B.; Thomas, A. P. Cell 1995, 82, 415-424.

(24) Gunter, T. E.; Buntinas, L.; Sparagna, G.; Eliseev, R.; Gunter, K. Cell Calcium 2000, 28, 285-296.

(25) Spät, A.; Szanda, G.; Csordás, G.; Hajnóczky, G. Cell Calcium 2008, 44, 51-63.

(26) Santo-Domingo, J.; Demaurex, N. Biochim. Biophys. Acta, Bioenerg. 2010, 1797, 907-912.

(27) Scholz, F.; Schroeder, U.; Gulaboski, R. Electrochemistry of Immobilized Particles and Droplets; Springer: Berlin, Heidelberg, 2005.

(28) Mirceski, V.; Komorsky-Lovric, S.; Lovric, M. Square-Wave Voltammetry, Theory and Application; Springer: Berlin, Heidelberg, 2008.

(29) Shi, C.; Anson, F. C. Anal. Chem. 1998, 70, 3114-3118.

(30) Shi, C. N.; Anson, F. C. J. Phys. Chem. B 2001, 105, 1047-1049. 
(31) Philipp, S.; Strauss, B.; Hirnet, D.; Wissenbach, U.; Mery, L.; Flockerzi, V.; Hoth, M. J. Biol. Chem. 2003, 278, 26629-38.

(32) Grynkiewicz, G.; Poenie, M.; Tsien, R. Y. J. Biol. Chem. 1985, 260, 3440-50.

(33) Rich, P. R.; Harper, R. Febs Lett. 1990, 269, 139-44.

(34) Morron, R. Biochemistry of Quinones; Academic Press Inc.: New York/London, 1965.

(35) Chambers, J. . The Chemistry of Quinonoid Compounds; John Wiley \& Sons: New York, 1974; pp 737-791.

(36) Rich, P. R. Biochim. Biophys. Acta, Bioenerg. 1981, 637, 28-33.

(37) Quan, M.; Sanchez, D.; Wasylkiw, M. F.; Smith, D. K. J. Am. Chem. Soc. 2007, 129, 12847-56.

(38) Ahmed, M.; Khan, Z. H. Spectrochim. Acta, Part A 2000, 56, 965-981.

(39) Lehtovuori, P.; Joela, H. J. Magn. Reson. 2000, 145, 319-325.

(40) MacMillan, F.; Lendzian, F.; Lubitz, W. Magn. Reson. Chem. 1995, 33, S81-S93.

(41) Pedersen, J. A. J. Chem. Soc., Perkin Trans. 2 1973, 424-431.

(42) Pedersen, J. A. Spectrochim. Acta, Part A 2002, 58, 1257-70.

(43) Ashworth, P.; Dixon, W. T. J. Chem. Soc., Perkin Trans. 2 1972, 1130-1133.

(44) Marchal, D.; Boireau, W.; Laval, J. M.; Moiroux, J.; Bourdillon, C. Biophys. J. 1997, 72, 2679-87.

(45) Bailey, S. I.; Ritchie, I. M. Electrochim. Acta 1985, 30, 3-12.

(46) Bernhardt, R. J. Biotechnol. 2006, 124, 128-145.

(47) Sono, M.; Roach, M. P.; Coulter, E. D.; Dawson, J. H. Chem. Rev. 1996, 96, 2841-2888.

(48) McLean, K. J.; Sabri, M.; Marshall, K. R.; Lawson, R. J.; Lewis, D. G.; Clift, D.; Balding, P. R.; Dunford, A. J.; Warman, A. J.; McVey, J. P.; Quinn, A. M.; Sutcliffe, M. J.; Scrutton, N. S.; Munro, A. W. Biochem. Soc. Trans. 2005, 33, 796-801.

(49) Meunier, G.; Meunier, B. J. Biol. Chem. 1985, 260, 10576-10582.

(50) Chakrabarty, S.; Bagchi, B. J. Phys. Chem. B 2009, 113, 8446-8448.

(51) Athawale, M. V.; Goel, G.; Ghosh, T.; Truskett, T. M.; Garde, S.

Proc. Natl. Acad. Sci. U.S.A. 2007, 104, 733-738.

(52) Quinzii, C. M.; et al. FASEB J. 2010, 24, 3733-43.

(53) Zampese, E.; Fasolato, C.; Kipanyula, M. J.; Bortolozzi, M.;

Pozzan, T.; Pizzo, P. Proc. Natl. Acad. Sci. U.S.A. 2011, 108, 2777-82.

(54) Giacomello, M.; Drago, I.; Bortolozzi, M.; Scorzeto, M.; Gianelle, A.; Pizzo, P.; Pozzan, T. Mol. Cell 2010, 38, 280-90.

(55) Willems, P. H. G. M.; Valsecchi, F.; Distelmaier, F.; Verkaart, S.; Visch, H.-J.; Smeitink, J. A. M.; Koopman, W. J. H. Cell Calcium 2008, $44,123-133$.

(56) Leo, S.; Szabadkai, G.; Rizzuto, R. Ann. N. Y. Acad. Sci. 2008, $1147,264-74$.

(57) Gunter, T. E.; Gunter, K. K.; Sheu, S. S.; Gavin, C. E. Am. J. Physiol. 1994, 267, C313-39.

(58) Perocchi, F.; Gohil, V. M.; Girgis, H. S.; Bao, X. R.; McCombs, J. E.; Palmer, A. E.; Mootha, V. K. Nature 2010, 467, 291-6.

(59) Jiang, D.; Zhao, L.; Clapham, D. E. Science 2009, 326, 144-7.

(60) Trenker, M.; Malli, R.; Fertschai, I.; Levak-Frank, S.; Graier, W. F. Nat. Cell Biol. 2007, 9, 445-52. 